Performance of U-Pu-Zr Fuel Cast Into Z1rcontum Molds*

by

ANL/FE/CP-76392

D. C. Crawford ${ }^{1}$, C. E. Lahm 1 , and H. Tsa $i^{2}$

DE93 004239

1 Fuels and Engineering Division

Argonne National Laboratory

Idaho Falls, Idaho 83403-2528

2Materials and Components Technology Division

Argonne National Laboratory

Chicago, Illinois 60439

October, 1992

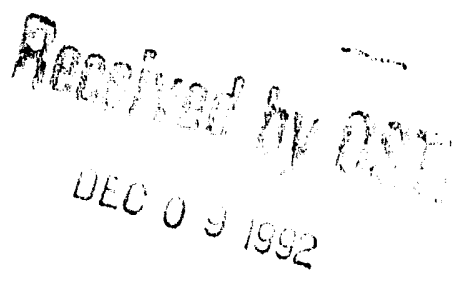

Paper presented at the

International Symposium on Fuels for Liquid Metal Reactors

as part of the ANS/ENS 1992 International Conference

Chicago, Illinois

November 15-20, 1992

and to be published in a special issue of the

Journal of Nuclear Materials

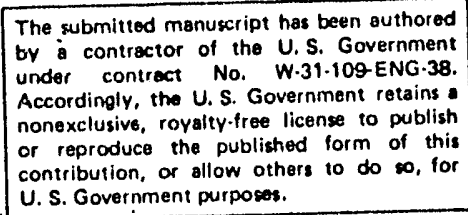

* Work supported by the U.S. Department of Energy. Office of Reactor Systems. Development and Technology, under contract W-31-109-Eng-38. 


\section{Performance of U-Pu-Zr Fuel Cast into Zirconium Molds*}

by

D. C. Crawford, C. E. Lahm, and H. Tsai

ABSTRACT

U-3Zr and U-20.5Pu-3Zr were injection cast into $\mathrm{Zr}$ tubes, or sheaths, rather than into quartz molds and clad in 316SS. These elements and standard-cast $U-10 Z r$ and U-19PU-10Zr elements were irradiated in EBR-II to 2 at.\% and removed for interim examination. Measurments of axial growth at indicate that the $2 r$-sheathed elements exhibited significantly less axial elongation than the standard-cast elements $(1.3$ to $1.8 \%$ versus 4.9 to 8.1 \%). Fuel material extruded through the ends of the $2 r$ sheaths, allowing the low-Zr iuel to contact the cladding in some cases. Transverse metallographic sections reveal cracks in the $Z r$ sheath through which fuel extruded and contacted cladding. The sheath is not a sufficient barrier between fuel and cladding to reduce FCCI, and any adverse effects due to increased FCCI will be evident as the elemenis attain higher burnup. 


\section{Introduction}

Current plans call for IFR fuel to be cast into quartz molds after reprocessing in the associated Fuel Cycle Facility (e.g. Seidel, et al. [1]). Because the quartz molds are destroyed during the fuel demolding process, the quartz residue must be treated as contaminated waste and is part of the IFR Fuel Cycle waste stream. Alternatively, if the fuel can be cast into molds that remain intact as an integral part of the fuel slugs (i.e.. if the fuel can be left inside the molds for irradiation). then the quartz mold contribution to the waste stream will be eliminated [2].

This possibility is being addressed in an on-going effort to evaluate the irradiation performance of fuel cast into zirconium tubes (or sheaths) rather than quartz molds. Zirconium was chosen as the sheath material because it is the component of the U-Pu-Zr fuel alloy that raises the alloy solidus temperature and provides resistance against fuel cladding chemical interaction (FCCI) [3]. Thus, the $2 \mathrm{r}$ sheath material was chosen to be compatible with the U-Pu-Zr fuel. In addition, the sheath was expected to reduce FCCI as wall as provide a mold alternative. This paper presents and discusses the irradiation performance of $2 r$-sheathed fue 1 elements irradiated in subassembly $\times 492$ to 2.0 at.\% burnup in EBR-II.

\section{Description of experiment}

Binary $(U-3 Z r)$ and ternary $(U-20.5 P u-3 Z r)$ fuel alloys were cast into $\mathrm{Zr}$ tubes in fuel fabrication facilities at Argonne National Laboratory in Idaho. The $2 r$ tubes were roughly $4.4 \mathrm{~mm} 0.0$. $\times 0.2 \mathrm{~mm}$ wall thickness: thus the sheathed slugs had the same diameter as standard-cast slugs. The $\mathrm{Zr}$ content of the melt was reduced to account for the $\mathrm{Zr}$ in the sheath. giving the sheathed slugs the same total $\mathrm{Zr}$ content as that in a standard-cast slug. Metallography of the as-cast fuel showed that the fuel alloy and the $2 r$ sheath interacted to form a metallurgical bond. The interaction layer extended roughly $12.7 \mu \mathrm{m}$ into the $\mathrm{Zr}$ sheath. 
The fuel elements made from the sheathed slugs were fabricated to MK-IIIA driver fuel parameters (see Lahm, et a1. [4]), with Type 316 stainless steel cladding tubes. The $2 r$-sheathed fuel elements and sibling standard-cast binary and ternary fuel elements (also fabricated to MK-IIIA parameters) were loaded into a 61 -element subassembly (designated $\mathrm{X} 492$ ) for irradiation in EBR-II. All of the ternary $\mathrm{Zr}$ sheathed elements and approximately half of the binary $2 r$-sheathed elements were made from two half-length fuel slugs rather than a single full-length slug. The remaining $2 r$-sheathed elements as well as the standard-cast elements contained a single full-iength slug. The nominal design parameters for the four types of elements loaded into the subassembly are listed in Table I.

The subassembly was irradiated in EBR-II core position $4 A 1$ to a peak burnup of 2.0 at.\%. A pretest analysis indicated that beginningof life fuel center line temperatures would range from 600 to $682^{\circ} \mathrm{C}$ and inside cladding temperatures would range from 502 to $551^{\circ} \mathrm{C}$. Table II lists the range of temperatures expected for each type of element. The peak fast fluence for the subassembly was calculated to be $1.7 \times 10^{22} \mathrm{n} / \mathrm{cm}^{2}$.

After removal from the reactor, the subassembly was taken to the Hot Fuel Examination Facility (HFEF) in Idaho where each of the 61 fuel elements were removed from the assembly and neutron radiographed. Metallic fuel exhibits significant swelling if unrestrained, and the radiographs were used to compare the axial elongation of $2 r$-sheathed and standard-cast elements. The lengths of the fuel slugs were measured from the radiographs and compared to the as-fabricated slug lengths (approximately $34.3 \mathrm{~cm}$ ). From these measurements, axial elongation was determined. After radiography six elements were chosen for destructive examination, while the remaining elements were reconstituted into subassembly $\times 492 \mathrm{~A}$ for further irradiation. Currently, the peak burnup of the reconstituted subassembly is approaching 6 at.\%.

The six elements removed from the subassembly consisted of two binary-sheathed elements, two ternary-sheathed elements, and a binary and a ternary element, each standard-cast. The diametral strains for five of these 
pins were measured using helical contact profilometry. Axial fission product distributions were found using axial gamma spectrometry. Following those non-destructive exams, plenum pressures and volumes were measured by puncturing and back-filling the elements using the HFEF gas sampling system [5].

One element of each type, plus an additional ternary Zr-sheathed element, was selected for metallographic examination at either HFEF or the Alpha Gamma Hot Cell Facility at Argonne National Laboratory in Illinois. All elements were examined at transverse sections near $X / 1=0.75$ (where $x$ is the axial position measured from the bottom of the fuel slug and $L$ is the ascast length of the slug). while the $2 r$-sheathed elements were additionaliy examined at transverse sections near $X / L \sim 0.25$ as well as longitudinal sections at the top or bottom of the fuel column or near $X / L=0.5$.

\section{Results}

\subsection{Neutron radiograph examination}

Examination of neutron radiographs of these elements revealed two interesting observations. First, measurements taken from neutron radiographs indicated that $2 r$-sheathed elements experienced significantly less axial elongation than did standard-cast elements. For both the sheathed and standard-cast elements, the binary alloy slugs grew more than did the ternary slugs, consistent with previous results [3]. The axial elongation measurements are summarized in Table III. Second, fuel material apparently grew out of the ends of the $\mathrm{Zr}$ sheaths. Thus the tops and bottoms of the fuel region in the elements. as well as the interface between the two slugs in the elements with segmented fuel, appeared to have fuel in position to contact the cladding.

\subsection{Contact profilometry}

Helical contact profilometry on the five elements (one element of each type plus an extra binary $2 r$-sheathed element) showed the diametral cladding strains to be similar for each type of element. The dilations are small. as expected for low burnup fuel elements, the maximum for all 
elements being approximately $0.020 \mathrm{~mm}$ above the nominal diameter $(\sim 0.35 \%$ diametral strain).

\subsection{Gamma scan}

Only a few notable features were observed in the axial gamma scans of the fuel elements. The $2 r$-sheathed elements exhibited spikes in Cs137 activity at the interface between the slugs at core midplane as well as at the top and bottom of the fuel column (for two of the three pins). indicating that the openings in the $2 r$ sheaths provided locations for the release of fission products and their subsequent dissolution in bond sodium. The non-sheathed elements exhibited high Cs-137 activity at and immediately above the top pf the fuel column as is typical. The $2 r$ sheathed fuel elements had narrow regions of relatively low $2 r-95$ and Nb-95 activity near the core midplane level, probably due to the separation of the two sheathed slugs at the slug interface.

\subsection{Fission gas analysis}

An analysis of fission gas sampled from four elements (one of each type) indicates that the fission gas released to the plenum of each element contains roughly $75 \% \mathrm{Xe}$ (mole percent) and $10 \% \mathrm{Kr}$. The sheathed pins exhibited essentially the same gas release behavior as the unsheathed pins (Table IV), with release fractions similar to those reported by Pahl, et al.. [3], for low burnup elements. The two ternary elements did have slightly higher gas release fractions than did the binary elements. Although a similar relation between $\mathrm{Pu}$ content and fractional gas release has been previously reported [6], only a small number of elements were examined for the present work. so the relation observed here may be anomalous.

\subsection{Metallographic examination}

Transverse sections of the $2 r$-sheathed elements (e.g. Figs. 1 and 2) near $X / L \sim 0.25$ and 0.75 reveal wedge-shaped longitudinal cracks or openings in the $\mathrm{Zr}$ sheath. presumably running down much of the length of the slugs. In each section, the $Z r$ sheath appears to have necked before splitting. The cracks in the $\mathrm{Zr}$ sheath on the ternary slug coincide with 
cracks that extend into the fuel alloy. Which appear to be simflar to those observed in a similar section of the standard-cast ternary element (Fig. 3). Such cracks have been previously observed in other U-19Pu-10Zr fuel elements irradiated to 2 at.\% burnup [6.7].

Although transverse sections of the standard-cast elements indicated no FCCI, some metallographic sections of Zr-sheathed elements did show evidence of FCCI - where fuel extruded through either the slug interface near the $X / L=0.5$ elevation or cracks in the $2 r$ sheath. Typically this interaction was confined to small areas, but penetrated about $20 \mu \mathrm{m}$ into the cladding of the ternary elements and about $10 \mu \mathrm{m}$ into the cladding of the binary elements.

Electron microprobe wavelength dispersive $x$-ray analysis (EMPA) was performed on sections of the ternary sheathed element shown in figures 2 and 4 . This analysis determined the $2 r$ concentration of the dense zone in the center of the element to be roughly $0.5 \mathrm{wt} \%$, depleted from the 3 wt $\% \mathrm{Zr}$ content of the as-cast fuel alloy; whereas the porous fuel lying between the $\mathrm{Zr}$ sheath and the dense center zone typically had enriched $\mathrm{Zr}$ contents of 5 to $6 \mathrm{wt} \%$. At the interface between the dense and the porous fuel zones, the $2 r$ content was the nominal 3 wt $\%$ of the as-cast fuel. The fuel approaching the cladding through a sheath crack was determined to have as little as $1.1 \mathrm{wt} \% \mathrm{Zr}$, and the fuel material next to the cladding at the slug interface in the longitudinal section of Fig. 4 was found to contain 6 wt $\%$ Zr.

Although the interaction between the fuel and the $\mathrm{Zr}$ sheath appears to be small in Figures 1, 2 and 3 , other sections show regions of extensive interaction. In fact, the longitudinal section in Fig. 4 shows a region where the entire $Z r$ sheath has apparently been attacked by interdiffusing fuel. The $2 r$ content at these peripheral regions varies from 100 wt $\%$ in the undisturbed $2 r$ sheath to 30 wt $\%$ at the inner portion of the attacked $\mathrm{Zr}$ sheath. At the interface between the attacked $\mathrm{Zr}$ sheath and the porous fuel the $2 r$ content is about 11 wt $\%$. 
Measurements taken from longitudinal sections of a ternary $2 r$ sheathed element indicated that the extrusion of fuel at the bottom of the fuel column raised the lower fuel slug approximately $0.8 \mathrm{~mm}$ above the lower end plug. Similarly, extrusion through the ends of the $Z r$ sheaths at the fuel slug interface (Fig. 4) separated the two slugs by about $2.3 \mathrm{~mm}$. The extrusion at the top of the fuel column was less severe, extending about $0.6 \mathrm{~mm}$ above the top of the sheath. Of the $5.2 \mathrm{~mm}$ axial elongation for that element. $3.7 \mathrm{~mm}$ was due to the displacement of the slugs upon extrusion of fuel through the ends of the sheaths.

\section{Discussion}

The two most striking results of the postirradiation examination of the $\mathrm{Zr}$-sheathed fuel are the reduced axial elongation and the wedge-shaped cracks observed in the $2 r$-sheathed elements. Those results will be discussed first followed by discussion of zone formation and the implications of the results.

The fuel $\mathrm{Zr}$-sheath interaction seen in the transverse section of the as-cast fuel slug indicates that the bond between the fuel and the sheath is a metallurgical bond that is uniform around the circumference. This is probably the characteristic of the $2 r$-sheathed fuel that restricted axial elongation. The Pu-containing slugs (both $2 r$ - sheathed and standard-cast) exhibited less elongation than the binary slugs, consistent with previously reported results [6.7] (this distinction is observed in elements irradiated at higher fuel temperatures). Hofman, et al. [7] suggested that higher Pu alloys exhibit less axial elongation because the three microstructural zones that form during irradiation have different swelling and diffusion properties that lead to higher radial swelling. Faster radial swelling causes the fuel slug to contact the cladding sooner in life than is the case for lower Pu alloys, and fuel-cladding contact restricts axial elongation [6].

One may have expected the $Z r$ sheaths to act as barriers to fission gas release, thus causing the $2 r$-sheathed slugs to retain more fission gas. However, the gas release fractions were the same for the $2 r$-sheathed elements as for the standard-cast elements. If the wedge-shaped cracks did 
in fact extend along the length of the slugs, then the cracks may have provided a path for fast release. Whether the path for gas release was through axial wedge-shaped cracks or simply through the exposed fuel at the open ends of the $\mathrm{Zr}$ sheaths, the implication is that the fuel porosity was interconnected sufficiently to allow gas release simflar to that of a nonsheathed fuel slug, which does exhibit interconnected porosity at this burnup [8]. Based on the lower axial growth values for the $Z r$-sheathed elements, one may not have expected interconnected porosity.

The origin of the wedge-shaped cracks is not obvious from the metallography. Wedge-shaped cracks have been found in standard-cast U-19Pu-10Zr fuel slugs irradiated to 2 at.\% burnup $[6,7]$. So, the crack in the ternary $\mathrm{Zr}$-sheathed element may have formed first in the fuel and then strained the $\mathrm{Zr}$ sheath to failure as the crack opened wider. However, no wedge-shaped cracks have yet been observed in standard-cast binary fuel. Therefore, the cracks present in the binary $2 r$-sheathed fuel likely formed first in the sheath as the fuel swelled radially, with continued fuel swelling splitting the sheath. This may have been the mode of fallure for the ternary Zr-sheathed slug as well: 1.e. the swelling fuel caused localized necking in the $2 r$ sheath, and the localized strain in the sheath may have induced the crack in the fuel rather than vice versa.

The metallographic sections of the $\mathrm{Zr}$-sheathed ternary elements near $X / L \sim 0.25$ and 0.75 show the fuel to have a two-zone structure. The inner (or center) zone is noticeably dense and has a $\mathrm{Zr}$ content of around 0.5 to 1 wt $\%$. The outer zone lies between the center zone and the $\mathrm{Zr}$ sheath and consists of porous fuel enriched in $\mathrm{Zr}$ (roughly 5 wt $\%$ ). This type of two-zone formation is similar to that seen in U-19Pu-10Zr elements at cooler axial locations, such as near the top and bottom of an element [8]. The hotter portions of those elements tended to form threezone structures, with a somewhat porous $\mathrm{Zr}$-enriched zone in the center, a dense $2 r$-depleted zone near mid-radius, and a porous slightly zr-enriched zone lying radially outward.

The $2 r$-sheathed fuel was irradiated at moderate termperatures and formed a two-zone structure rather than a three-zone structure at a relatively hot axial location $(X / L-0.75)$. This zone formation behavior 
is probably a result of the phase equilibria expected in this alloy at the irradiation temperature. U-20.5Pu-3Zr (the $\mathrm{Zr}$-sheathed fuel alloy) contains significantly less $2 r$ in the alloy and may have different phases stable at irradiation temperatures than does fuel containing 10 wt $\% \mathrm{Zr}$. A pretest thermal analysis predicted a centerline temperature for the sectioned element of Figures 2 and 4 near $670^{\circ} \mathrm{C}$. Ternary phase diagrams show that at $670^{\circ} \mathrm{C}$ both U-20.5PU-3Zr and U-19Pu-Zr lie in a predominantly $\gamma$ region of the phase diagram. while at $650^{\circ} \mathrm{C}$ both lie in the $\gamma+\zeta$ region [9]. However, at $660^{\circ} \mathrm{C}$ for example, the 10 wt $\% \mathrm{Zr}$ alloy exists predominantly in the $\gamma_{1}+\gamma_{2}$ phases while the 3 wt $\%$ Zr alloy has $\gamma+\zeta$ phases stable. Therefore, a U-20.5Pu-3Zr element has less $\gamma$ phase in its center zone and more $\zeta$ phase than does a U-19Pu-10Zr element. This is significant, in that, the $\gamma+\zeta$ two-phase region has previously been identified as the $Z r$-depleted zone of a U-19Pu-10Zr element with three zones [10]. The present results consistently show that the zone in the $Z \mathbf{r}$ sheathed element (i.e. the center zone) expected to have the $\gamma+\zeta$ phases stable at irradiation temperatures is also $\mathrm{Zr}$-depleted.

The $\mathrm{Zr}$-depleted zone in the $\mathrm{Zr}$-sheathed fuel slug is potentially a source of concern. Because the fuel alloy has less $Z r$ initially than the standard-cast fuel, further depletion of $\mathrm{Zr}$ to concentrations less than the as-cast 3 wt.\% will lower the local solidus temperature to values less than that of a $Z r$-depleted zone in a U-10Zr alloy. Although that is not expected to be a problem under steady state operation. it may be of concern for off-normal events.

Two potential advantages of the $Z r$ sheath concept remain. First, fuel elements can be cast into $\mathrm{Zr}$ tubes, eliminating the need for quartz molds. Second, the $2 r$ sheaths appear to reduce axial growth (at low burnup where most of the axial elongation occurs [3]) to strains below $2 \%$. Although the results show that $2 r$ sheaths in the form tested here cannot be a reliable barrier to FCCI, no performance problems due to FCCI have been identified at low burnup. Irradiation to higher burnup is required to assess the consequences of $10 w-Z r$ fuel making contact with cladding. If the low-Zr fuel in the sheathed elements does in fact interact with cladding in a manner that causes premature failure, then variations of the concept can still be pursued. For example, the $2 r$ content of the fuel 
alloy can be increased to an amount that reduces FCCI in regions where fuel alloy extrudes through openings in the $2 r$ sheath.

\subsection{Cenclusions}

1. Zr-sheath fuel elements irradiated to 1.8 at.\% burnup exhibit significantly less axial growth that standard-cast fuel elements. This is beneficial for reactor reactivity considerations.

2. The prospects of reduced axial growth and of eliminating quartz debris from the FCF waste stream, are sufficient to warrant further investigation of the sheathed fuel concept.

3. A $0.2 \mathrm{~mm}$ thick $Z r$ sheath around a U-20.5Pu-3Zr fuel alloy does not provide a reliable barrier against FCCI under irradiation, but irradiation to higher burnup is required to determine if this is important.

\section{Acknowledgements}

The authors are grateful to personnel at the Hot Fuel Examination Facility and the Aipha Gamma Hot Cell Facility for the assistance with the post-irradiation examination. The efforts of D.B Tracy. R.W. Keyes and the fuel fabrication personnel are also appreciated. 


\section{References}

1. B. Seidel, L. Walters, and Y. Chang, J. of Metals 39 (1987) 10.

2. B. R. Seidel, D. B. Tracy, and V. Griffiths, U. S. Patent No. 5,044,811 (September 3, 1991).

3. R. G. Pahl, D. L. Porter, C. E. Lahm, and G. L. Hofman, Met. Trans. A 21A (1990) 1863.

4. C. Lahm, J. Koenig, D. Porter, R. Pahl, and D. Crawford, "Experience with Advanced Oriver Fuels in EBR-II," this proceedings.

5. R. Wisner, Proc. 36th Conference on Remote Systems Technology (American Nuclear Society. LeGrange Park. Illinois, 1988) p. 69.

6. R. G. Pahl, C. E. Lahm, R. Villarreal, W. N. Beck, and G. L. Hofman. Proc. of International Conference on Reliable Fuels for Liquid Metal Reactors (American Nuclear Society. LeGrange Park, Illinois, 1986) p. 3-36.

7. G. L. Hofman, R. G. Pahl, C. E. Lahm, and D. L. Porter, Met. Trans. A 21A (1990) 517.

8. R. G. Pahl, R. S. Wisner, M. C. Billone, and G. L. Hofman. Proc. of the 1990 International Fast Reactor Safety Meeting Vol. IV (American Nuclear Society, LeGrange Park. Illinois, 1990) P. 129.

9. D. R. O'Boyle and A. E. Dwight, in: Plutonium 1970 and Other Actinides, ed. William N. Miner (TMS-AIME, Metals Park. Ohio, 1970). p. 720 ,

10. D. L. Porter, C. E. Lahm, and R. G. Pahl. Met. Trans. A $21 \mathrm{~A}$ (1990) 1871. 
Table 1. Nominal Design Parameters for $2 r$-sheathed Fuel Irradiation Experiments

\begin{tabular}{|c|c|c|c|c|}
\hline Element Type & $\begin{array}{c}\text { Binary } \\
\text { std. cast1 }\end{array}$ & $\begin{array}{c}\text { Binary } \\
Z r \text {-sheathed }\end{array}$ & $\begin{array}{c}\text { Ternary } \\
\text { std.Cast }\end{array}$ & $\begin{array}{c}\text { Ternary } \\
Z \text {-sheathed }\end{array}$ \\
\hline Fuel Alloy (wt.\%) & $U-10 Z r$ & $U-3 Z r$ & $U-19 P u-10 Z r$ & $U-20.5 P u-3 Z r$ \\
\hline Cladding \& Wire & $316 S S$ & $316 S S$ & $316 S S$ & $316 S S$ \\
\hline Bond & Na & Na & Na & Na \\
\hline Clad 0.0. (mm) & 5.8 & 5.8 & 5.8 & 5.8 \\
\hline Clad Wall (mm) & 0.4 & 0.4 & 0.4 & 0.4 \\
\hline Element Length (cm) & 74.9 & 74.9 & 74.9 & 74.9 \\
\hline Fuel Slug 0.0.2 (mm) & 4.4 & 4.4 & 4.4 & 4.4 \\
\hline Zr Sheath Wall (mm) & - & 0.2 & - & 0.2 \\
\hline Slug Length (cm) & 34.3 & $34.3 / 2017.1$ & 34.3 & $2 @ 17.1$ \\
\hline $\begin{array}{c}\text { Simear Density } \\
\text { Plenum/Fuel } \\
\text { Vol. Ratio } \\
\text { (as -built) }\end{array}$ & $75 \%$ & $75 \%$ & $75 \%$ & $75 \%$ \\
\hline
\end{tabular}

1. Standard MK-IIIA driver elements.

2. Sheath 0.0 . for $2 r$-sheathed elements. 
Table II. Ranges of Beginning-of-Life Peak Centerline and Peak Inner Cladding Temperatures for $2 r$-sheathed Fuel Irradiation Experiment

\begin{tabular}{|c|c|c|c|c|}
\hline Element Type & $\begin{array}{c}\text { Binary } \\
\text { std. cast }\end{array}$ & $\begin{array}{c}\text { Binary } \\
\text { Zr-sheathed }\end{array}$ & $\begin{array}{c}\text { Ternary } \\
\text { std. cast }\end{array}$ & $\begin{array}{c}\text { Ternary } \\
\text { Zr-sheathed }\end{array}$ \\
\hline Peak Centerline $\left({ }^{\circ} \mathrm{C}\right)$ & $604-678$ & $603-671$ & $605-682$ & $600-680$ \\
\hline Peak Inner Clad $\left({ }^{\circ} \mathrm{C}\right)$ & $511-544$ & $503-551$ & $502-551$ & $502-551$ \\
\hline
\end{tabular}

Table III. Summary of Axial Growth Results for Zr-sheathed and Standard-cast Elements

\begin{tabular}{|c|c|c|c|}
\hline Element Type & No. of Elements & Avg. \% Ax. Growth & Std. Dev. \\
\hline $\begin{array}{c}\text { U-3Zr } \\
\text { Segmenthed }\end{array}$ & 15 & 1.79 & 0.39 \\
\hline $\begin{array}{c}\text { U-3Zr } \\
\text { Un-sheathed } \\
\text { Unsegmented }\end{array}$ & 13 & 1.34 & 0.24 \\
\hline $\begin{array}{c}\text { U-10zr } \\
\text { Unsegmented }\end{array}$ & 13 & 8.07 & 0.51 \\
\hline $\begin{array}{c}\text { U-20.5Pu-3zr } \\
\text { Zr-sheathed } \\
\text { Segmented }\end{array}$ & 12 & 1.23 & 0.22 \\
\hline $\begin{array}{c}\text { U-19Pu-10zr } \\
\text { Unsegmented }\end{array}$ & 8 & 4.93 & 0.38 \\
\hline
\end{tabular}


Table IV. Gas Release Characteristics for Zr-sheathed and Standard Cast Elements

\begin{tabular}{|c|c|c|c|c|}
\hline Element $1 . D$. & Description & Burnup (at .\%) & $\begin{array}{c}\text { Plenum } \\
\text { Pressure } \\
\text { (psia) }\end{array}$ & $\begin{array}{c}\text { Percent Fission } \\
\text { Gas Release } 2\end{array}$ \\
\hline M918 & $\begin{array}{c}U-102 r \\
\text { std. Cast } \\
\end{array}$ & 1.8 & 60 & 53 \\
\hline L490 & $\begin{array}{c}U-3 Z r \\
Z r-S h e a t h e d\end{array}$ & 1.9 & 62 & 56 \\
\hline K067 & $\begin{array}{c}U-19 P u-10 Z r \\
\text { std. Cast }\end{array}$ & 1.8 & 66 & 60 \\
\hline K082 & $\begin{array}{l}U-20.5 P u-3 Z r \\
Z r-S h e a t h e d\end{array}$ & 1.9 & 68 & 67 \\
\hline
\end{tabular}

1 Temperature at approximateiy $30^{\circ} \mathrm{C}$. Includes tag and fill gas.

2 Assumes 0.25 atoms fission gas per atom fissioned. 


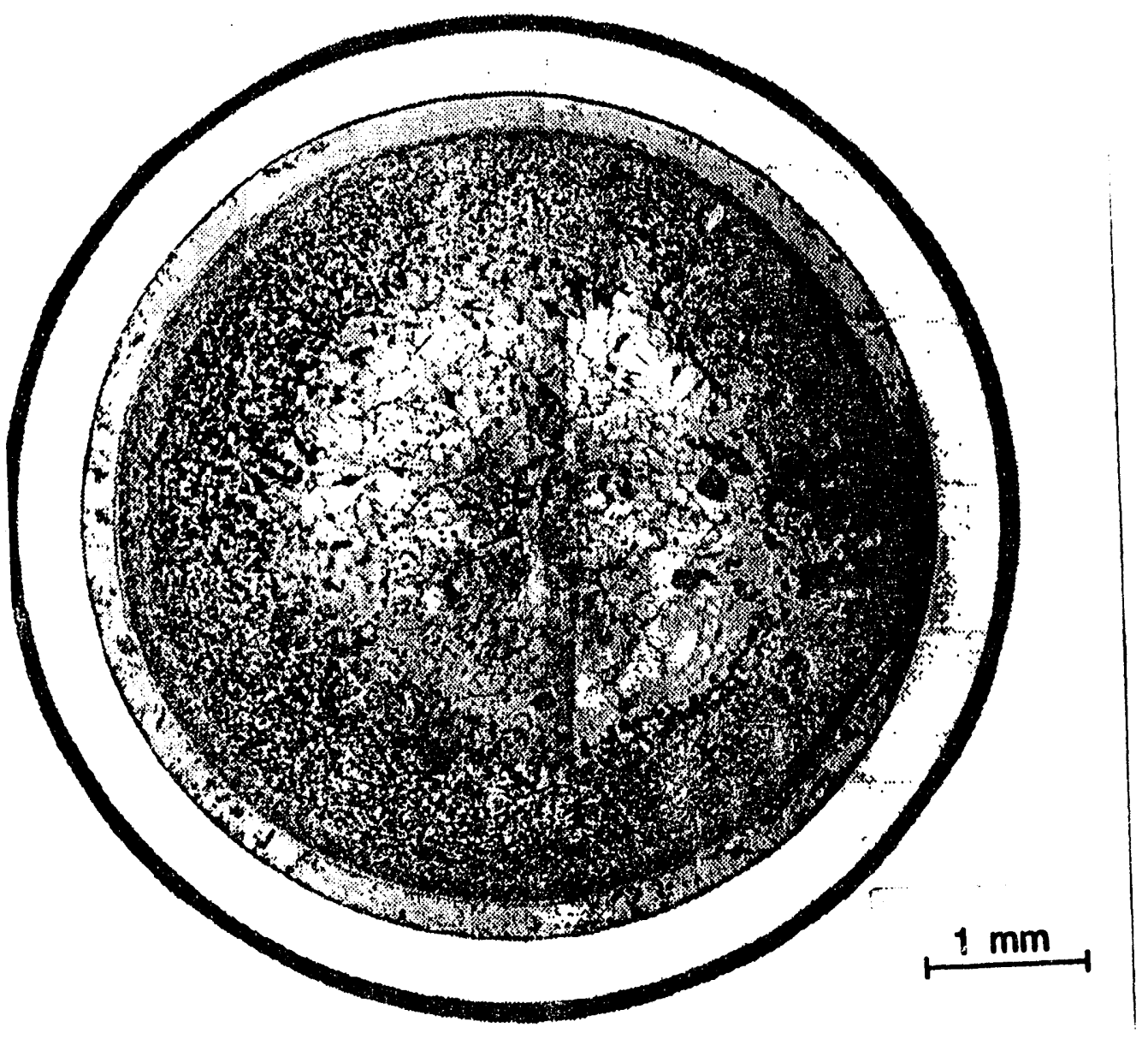

Figure 1. Tranverse section of $2 r$-sheathed $U$-3Zr element near $X / L \sim 0.75$. The dark portions of the $2 r$ sheath are artifacts from grinding and polishing of the soft $2 r$ material. 


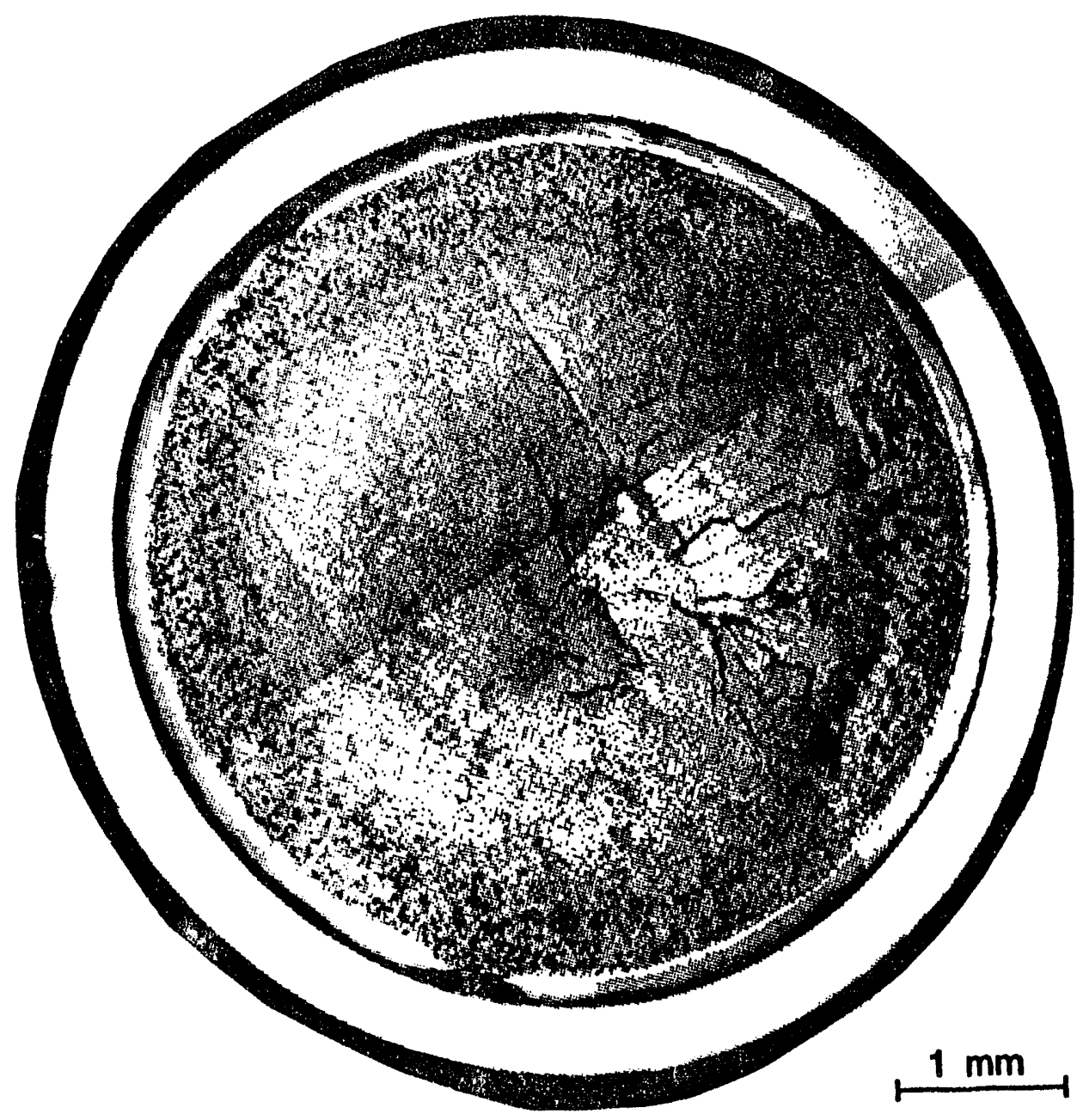

Figure 2. Tranverse section of a $2 r$-sheathed U-20.5Pu-3Zr element near $X / L \sim 0.75$. Again, the dark spots in the $\mathrm{Zr}$ sheath are artifacts from grinding and polishing. 


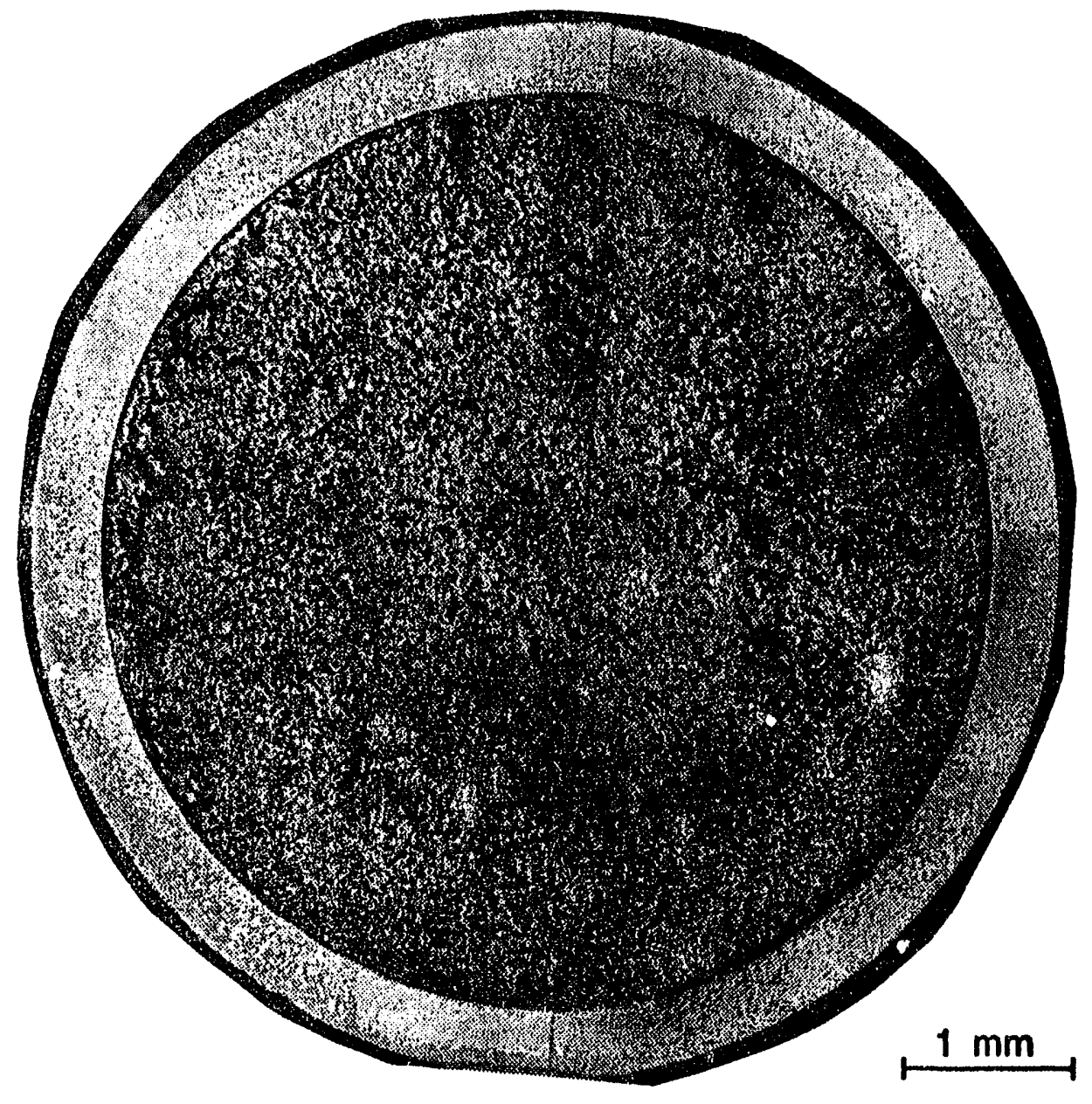

Figure 3. Tranverse section of a standard-cast U-19Pu-10Zr element near $X / L \sim 0.75$. 


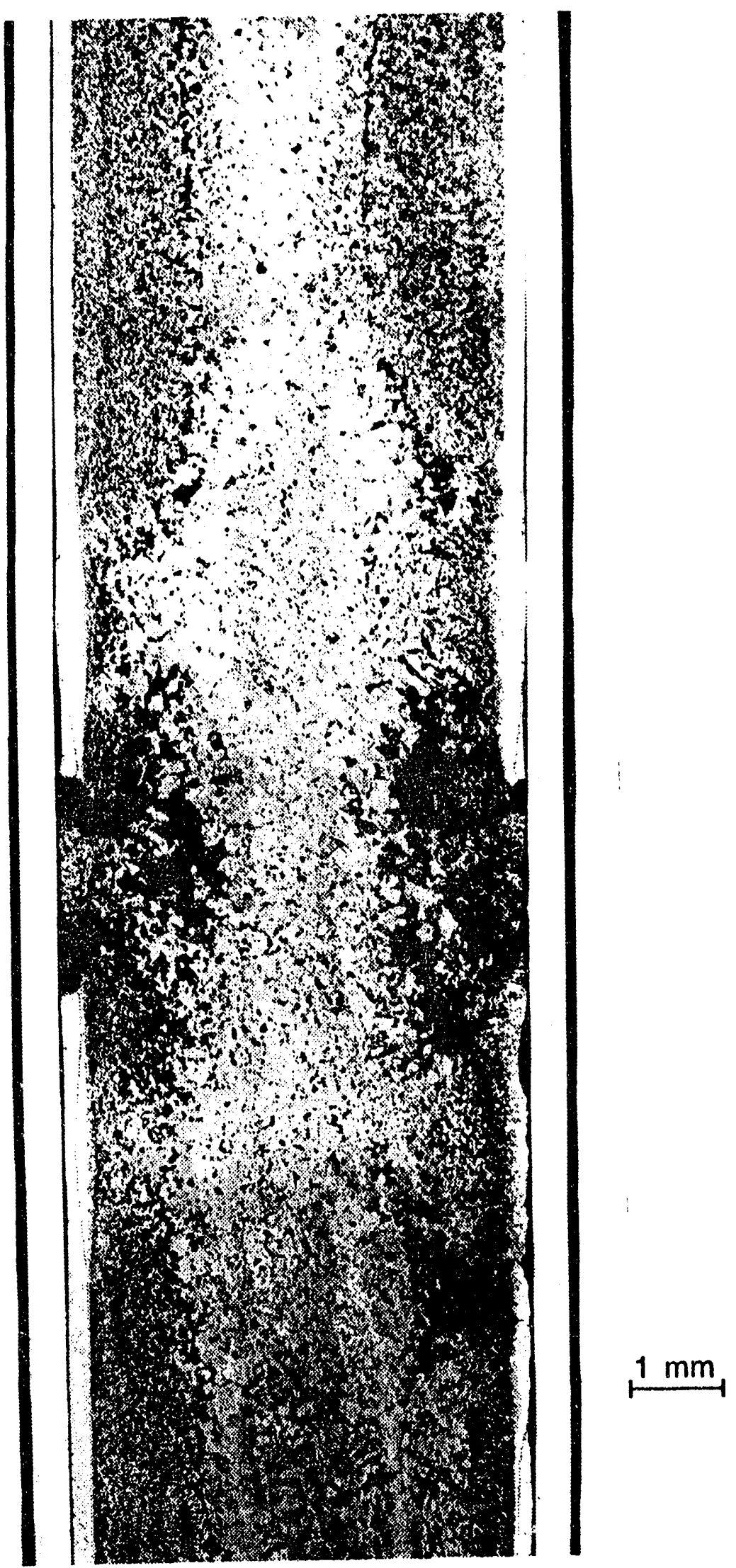

Figure 4. Longitudinal section of a $\mathrm{Zr}$-sheathed $\mathrm{U}-20.5 \mathrm{Pu}-3 \mathrm{Zr}$ element near $X / L=0.50$. 

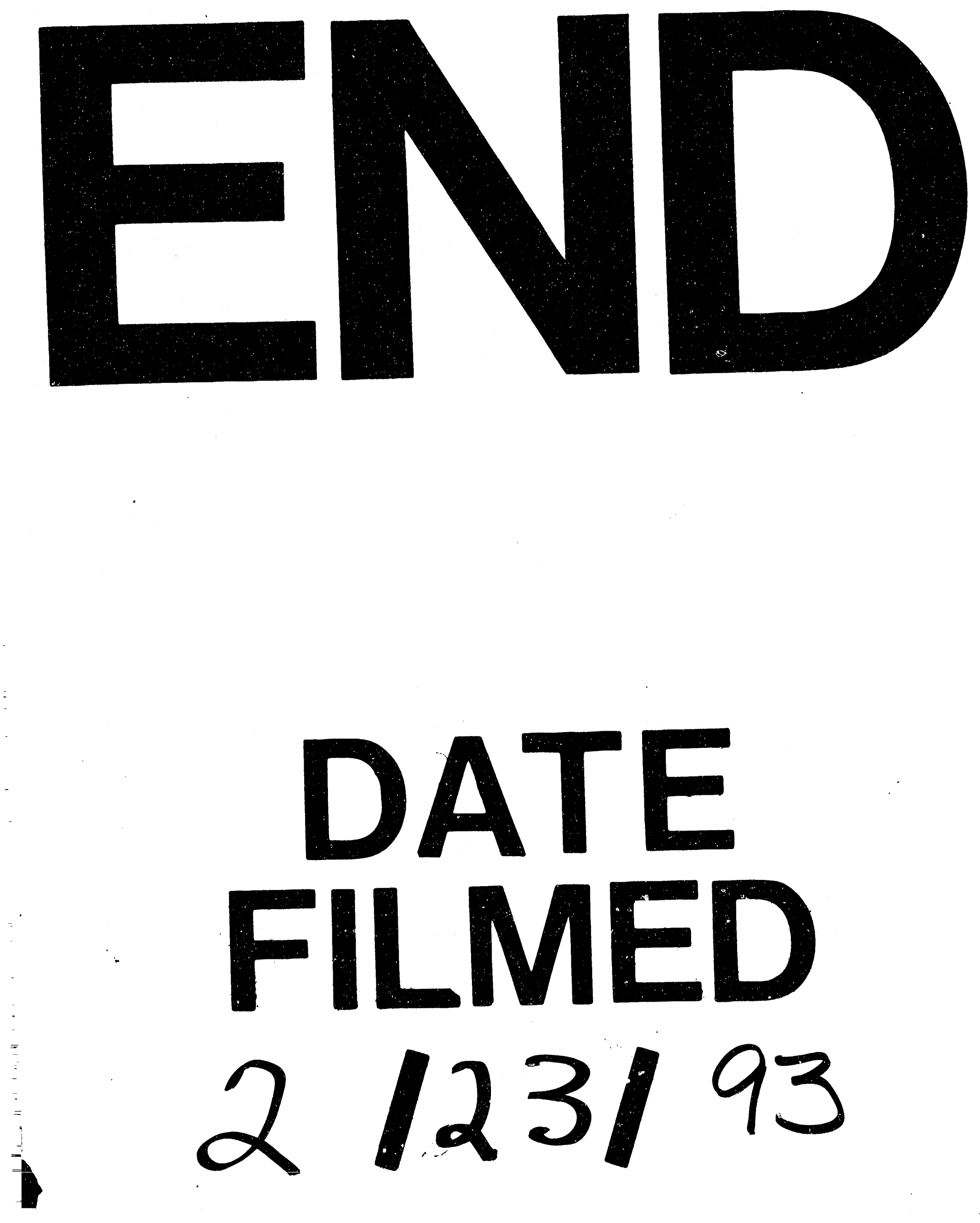
